\title{
Why subaltern language? Yes, we speak Portuguese! PARA UMA CRÍTICA DA COLONIALIDADE DA LÍNGUA NA MOBILIDADE ESTUDANTIL INTERNACIONAL
}

\author{
Rovênia Borges \& Almerindo Janela Afonso
}

\begin{abstract}
Resumo
Comunicar fluentemente em língua inglesa, possibilidade vulgarmente associada à condição de classe social e à posse de outros bens posicionais, tornou-se uma das principais vantagens competitivas para participar de programas de estudo e de pesquisa em universidades bem localizadas nos rankings académicos. A nível mais geral, face às desigualdades sociais e educacionais, nomeadamente em Portugal e no Brasil, a hegemonia da língua inglesa constitui um obstáculo para os países de língua portuguesa que investem em políticas de internacionalização para a qualificação avançada de pesquisadores em áreas científicas, nomeadamente naquelas que induzem inovação e trazem mais-valias para a economia do conhecimento. Sob perspetiva comparada, e tendo em conta alguns pressupostos das teorias críticas pós-coloniais, este artigo faz uma reflexão sobre como as políticas da língua inglesa nos países acima referidos contribuem para reforçar desigualdades e desvantagens para muitos candidatos a programas de mobilidade científica internacional.
\end{abstract}

Língua inglesa; Brasil/Portugal; internacionalização; desigualdades; colonialidade

\section{WhY SUBALTERN LANGUAGE? YES, WE SPEAK Portuguese! For a CRITIQUe OF THE COLONIALITy OF LANGUAGE IN INTERNATIONAL STUDENT MOBILITY}

\begin{abstract}
The ability to communicate in English is often associated with the condition of social class, gender and other factors of cultural identity. In this early $21^{\text {st }}$ century, it has become one of the main constraints to participate in study and research programs in universities with top academic rankings. However, in many countries with too many educational inequalities, namely in Portugal and Brazil, the hegemony of the English language is a worrying factor for the internationalisation policies aimed at the high qualification of researchers in several scientific areas, especially those that lead to innovation and bring added value to the knowledge economy. From a comparative perspective, and taking into account some assumptions of postcolonial critical theories, this article presents a critical reflection on how English language teaching policies in the countries mentioned have acted to reinforce inequalities in terms of international student mobility.
\end{abstract}

\section{KEYWORDS}

English language; Brazil/Portugal; internationalisation; inequalities; coloniality 


\section{SOB A COLONIALIDADE DA LÍNGUA FRANCA DO CONHECIMENTO}

Apesar do anterior poder económico, cultural e militar do Império Britânico, foi depois da II Guerra Mundial que o inglês alcançou o predomínio que hoje tem como veículo linguístico de suporte às múltiplas interações internacionais. Com efeito, com o fim do conflito, e na condição de países "vitoriosos", os Estados Unidos e a Inglaterra adotaram estratégias, que apesar de contestadas e contestáveis, têm sido eficazes para construir e manter a atual hegemonia da língua inglesa. A isso não foi indiferente o acelerar das dinâmicas da globalização, que tem contribuído fortemente para que o inglês se continue a afirmar como língua franca' nas relações internacionais (políticas, económicas, comerciais, científicas, culturais, educacionais...), tornando-se também veículo dominante de intercâmbio e colaboração nas (e entre as) diversas instituições de ensino superior e centros de investigação de diferentes países.

Como corolário da sua irradiação ampliada à escala global, o inglês estende-se hoje a distintas dimensões da vida social, muitas das quais estão impregnadas de um visão hegemónica euro (norte)americana, genericamente referenciável à colonialidade do poder - expressão usada pelo sociólogo peruano Aníbal Quijano (2002, p. 4) para se referir a uma matriz, ou "padrão mundial de poder", que inclui como elementos constitutivos articulados as formas de dominação pela estratificação social racializada, pela exploração capitalista do trabalho e pelo modo euro (norte) americano ${ }^{3}$ de produzir conhecimento científico e tecnológico.

Para autores de estudos pós-coloniais latino-americanos, a colonialidade expande-se, nomeadamente a partir do século XVI, com a chegada dos conquistadores ibéricos às Américas, iniciando a inculcação prosélita e violenta de crenças de raiz religiosa, e impondo outras línguas, culturas e visões do mundo, (auto)justificadas pela suposta supremacia da nascente modernidade europeia. Desenvolve-se inicialmente, a partir daí, a matriz colonial de poder que esteve sob a liderança de Portugal e Espanha entre 1500 a 1750, na fase católica-ibérica da modernidade e de domínio da rota mercantil mais rentável do globo, o Atlântico Sul (Barrantes-Monteiro, 2018, p. 10). Entretanto, a partir do século XVIII com a ascensão económica da Inglaterra, França e Alemanha sobre o sul europeu, o Português e o Espanhol, enquanto línguas vivas de dois impérios ibéricos em declínio, começam a perder gradativamente força.

Mas independentemente desta alteração nas relações de força coloniais, o facto é que, após o fim (formal ou convencional) do colonialismo europeu, as suas heranças

\footnotetext{
'Língua franca significa dizer que é o idioma usado "como linguagem de contato entre falantes de diferentes línguas" (Jenkins, 2015, p. 56). Esse papel já foi desempenhado pelo latim, que era a língua culta e de prestígio social ensinada até aproximadamente os séculos XVI-XVII, quando foi paulatinamente sendo substituída pelas "línguas francas dos Descobrimentos e das subsequentes potências imperialistas" (Martins \& Cardoso, 2015, p. 141).

${ }^{2}$ Walter Mignolo (2010, p. 12) acresce que a matriz colonial é uma estrutura complexa de distintos níveis de colonialidade de poder entrelaçados, a fim de obter o controle da economia, da autoridade (Estado), da natureza e dos recursos naturais, do género e da sexualidade, da subjetividade e do conhecimento (forma de pensar e de produzir conhecimento).

${ }^{3}$ Segundo Silva Júnior (2017, p. 14), desde meados dos anos 1990, tanto as universidades europeias, com o Processo de Bolonha, quanto as brasileiras, com a política neoliberal adotada nos governos de Fernando Henrique Cardoso, passaram por um "processo de significativa mutação em direção ao modelo anglo-saxônico sob hegemonia da versão americana". Por isso, em vez de eurocentrismo optámos por atualizar o termo euro(norte)americano, inspirados em Quijano.
} 
ideológicas e os seus instrumentos culturais de opressão continuaram a interferir fortemente nas relações sociais no Brasil e demais países, nomeadamente latino-americanos e africanos. Fora do período histórico do colonialismo, mas continuando marcado pela colonialidade do poder, o Inglês segue a consolidar-se como língua franca da produção e disseminação do conhecimento técnico e científico, em diferentes áreas, funcionando também, e cada vez mais, como instrumento de construção de novas subjetividades e de novas formas cognitivas de perceber e interpretar o mundo. Neste sentido, "na divisão internacional do trabalho intelectual", como assinala Robert Stam, a tendência que se mantém, desde o início da modernidade histórica, é a do crescente domínio cultural e científico eurocêntrico (supostamente) mais avançado que outros conhecimentos e culturas, exaltando "os pensadores do Norte Global em detrimento dos pensadores do Sul Global" (Stam em entrevista a Santos \& Schor, 2013, p. 703).

Também nas últimas três décadas, a hegemonia da língua inglesa passa a ser um dos esteios do boom da internacionalização (capitalista) do ensino superior. Entre outras razões, o fluxo mais intenso de estudantes que cruzam as fronteiras nacionais pode ser explicado não apenas pelas novas oportunidades abertas pela globalização, mas também porque muitas famílias, sobretudo das novas classes médias, apostam na internacionalização dos estudos dos seus filhos (Nogueira, 2017) e "acreditam que as qualificações estrangeiras são mais valiosas que as “locais'” (Lasanowski, 2013, p. 199). Por conseguinte, as rotas de estudantes internacionais voltam-se predominantemente para instituições com oferta de cursos em língua inglesa, sendo as mais prestigiadas as que estão (ou procuram estar) nos melhores lugares dos rankings mundiais.

Dados disponíveis online no site oficial da Unesco (Institute for Statistics, 2018) apontam os Estados Unidos e o Reino Unido como os países que mais recrutam estudantes internacionais ${ }^{4}$. Para além da mobilidade recíproca entre estes países, nota-se ainda que, a partir deles, as opções vão também em direção a outros países capitalistas anglófonos 5 . No que diz respeito às rotas de mobilidade internacional rumo ao Brasil, o referido levantamento estatístico indica a procura deste país por parte de 19.855 estudantes de 199 distintas nacionalidades, sendo as origens mais expressivas Angola (2.317), Colômbia (1.627), Peru (1.409), Paraguai (1.082) e Argentina (1.061). Portugal surge em oitavo, com 806 estudantes internacionais e os Estados Unidos, em décimo, com 663 estadunidenses ${ }^{6}$ ). No sentido inverso, o Brasil enviou mais do que o dobro de estudantes para o exterior (43.438), sendo os EUA o principal destino com 13.349, seguindo-se Portugal com 6.372 estudantes, França com 4.311, Alemanha com 3.790 e Reino Unido com 2.713.

\footnotetext{
4 De acordo com mapa online Global Flow of Tertiary-Level Students (Unesco Institute for Statistics, 2018), consultado em 30 de abril de 2018, os EUA receberam 907.251 estudantes internacionais a nível de graduação e pós-graduação, que estudaram no exterior por um período de pelo menos um ano, sendo 291.063 da China, 112.714 da Índia e 63.952 da Coreia do Sul. No fluxo inverso, enviaram 68.580 alunos para estudar fora, sendo o Reino Unido o principal destino (15.378), seguido pelo Canadá (8.355) e Granada, no Caribe (4.543). O Reino Unido, por sua vez, hospedou 430.687 estudantes internacionais, grande parte chineses (91.518), indianos (18.177) e nigerianos (17.881). Na mobilidade inversa, os principais destinos foram EUA (9.601), Austrália (2.019), França (1.995), Alemanha (1.798).

5 Dos três primeiros destinos da mobilidade internacional de estudantes dos EUA, $41,1 \%$ eram países de língua inglesa: Reino Unido, Canadá e Grenada. Os EUA posicionaram-se como o principal país anfitrião dos estudantes do Reino Unido, respondendo por $29 \%$ do fluxo (Unesco Institute of Statistics, 2018).

${ }^{6}$ Dados referentes ao Brasil são de 2015 (Unesco Institute for Statistics, 2018).
} 
$\mathrm{Na}$ análise da mobilidade internacional restrita a Portugal7, verificou-se um fluxo ligeiramente maior de estudantes recebidos (16.888) em relação aos enviados para o exterior (12.335). O principal país de origem dos estudantes internacionais foi o Brasil (6.372), seguido de Angola (2.761). Estes dados mostram que 54\% dos estudantes internacionais que frequentam instituições de ensino superior em Portugal são falantes da língua portuguesa e provenientes das suas duas maiores ex-colónias. Por sua vez, Brasil e Angola não estão entre os principais países de destino dos portugueses, que optam por estudar no Reino Unido (2.709) e França (1.857), seguindo-se a Espanha (1.586) e os Estados Unidos (887). O Brasil surge apenas no quinto destino de preferência (806).

Há, obviamente, uma conjunção de fatores a influenciar o desenho das rotas, tais como a condição económica dos estudantes, a proximidade geográfica ou histórico-cultural entre os países, fatores relacionados com o clima e com a segurança, e a indução dos rankings mundiais de universidades ${ }^{8}$. Porém, não podemos deixar de considerar uma nova forma de colonialidade de poder moldada no mapa-múndi da mobilidade internacional, e que se serve da hegemonia do inglês para acesso a centros científicos e tecnológicos de excelência nos Estados Unidos, Reino Unido ${ }^{9}$, Canadá, Austrália, bem como a instituições de referência situadas em países não anglófonos, a exemplo da Alemanha, que passaram a oferecer cursos em língua inglesa como estratégia comercial de recrutamento (Lasanowski, 2013, p. 204), ou seja, enquanto "negócio de exportação" (Holford, 2014, p. 22).

Nas Américas, o "poder" de atração de estudantes internacionais está, conforme as estatísticas da Unesco, fortemente concentrado nos Estados Unidos e a receita gerada a partir desta mobilidade revela-se "intrinsecamente ligada às economias nacionais, regionais e estaduais" (Spears, 2014, p. 155). Por conseguinte, Estados Unidos e Reino Unido destacam-se como os destinos mais populares no mapa-múndi das rotas da mobilidade, constituindo-se espécies de Mecas do Conhecimento para onde fluem "três em cada dez estudantes internacionais atualmente" (Lasanowski, 2013, p. 195).

No entanto, Estados Unidos e Reino Unido não despontam como países que mais estudantes enviam para o exterior, posição ocupada pela China, Índia e Alemanha ${ }^{10}$. Por este prisma, como se pode perceber, as rotas de mobilidade internacional evidenciam muitos desequilíbrios. Mesmo entre os países com posições semiperiféricas no contexto mundial, os dois sentidos de uma mesma rota de mobilidade mostram-se bastante assimétricos. Embora Brasil e Portugal tenham os EUA e o Reino Unido, em grande

\footnotetext{
7 Dados referentes a Portugal são de 2016 (Unesco Institute for Statistics, 2018).

${ }^{8}$ Referente aos fatores a influenciar a mobilidade de estudantes portugueses, apesar do apoio financeiro da União Europeia com a concessão de bolsas, "o custo de vida e a distância geográfica ainda são relevantes para explicar os fluxos de estudantes entre países" (Cunha \& Santos, 2017, p. 56).

${ }^{9}$ Desde o Processo de Bolonha, na virada do século, as universidades e o governo do Reino Unido empenham-se no recrutamento de estudantes de fora da Europa, sendo as propinas pagas pelos estudantes uma importante fonte de receita - 0 valor ronda os 11 mil euros por ano, o "mais alto da União Europeia" (Viana, 2018, p. 14).

${ }^{10}$ Entre os países que mais hospedaram estudantes internacionais estão os Estados Unidos (907.251), seguido pelo Reino Unido (430.687) e Austrália (335.512), todos falantes da língua inglesa. China (847.259), Índia (278.383) e Alemanha (117.921) são os que apresentaram maior quantitativo de estudantes no exterior (Unesco Institute for Statistics, 2018).
} 
medida, como países anfitriões dos seus programas de mobilidade, apenas 1,3\% de estudantes estadunidenses e $0,7 \%$ dos britânicos escolheram, no período analisado, estudar em instituições brasileiras e portuguesas. No sentido oposto, $38 \%$ de brasileiros e portugueses foram para instituições de ensino e pesquisa sediadas nos EUA e $28 \%$ no Reino Unido (Unesco Institute for Statistics, 2018).

Esta última tendência não deixa, de algum modo, de revelar que as universidades brasileiras e portuguesas, tal como as de muitos países semiperiféricos e periféricos na perspetiva da economia mundial, estão longe de admitir outra alternativa que não seja a subordinação às premissas de uma colonialidade epistemológica técnico-científica euro(norte)americana. Estamos a tentar perceber criticamente o "dark side emergente na universidade", que traduz uma rutura com o seu ethos enquanto instituição moderna assente "numa ampla visão ética, educativa e cultural" para uma organização de tipo empresarial que se guia cada vez mais por "interesses espúrios do capitalismo, crescentemente internacionalizado" (Afonso, 2017, p. 8). Dado o facto de a mobilidade estudantil ocorrer predominantemente do lado de cá da linha do pensamento abissal, (para usar a expressão de Boaventura Sousa Santos), nesta fase atual de hegemonia epistémica do Norte, o conhecimento científico produzido pelos países centrais é inevitavelmente o mais procurado. Neste sentido, do nosso ponto de vista, a rutura com os atuais padrões de mobilidade internacional no campo do estudo e da pesquisa só poderá ocorrer quando muitos países deixarem de ser apenas consumidores e passarem a ser também produtores de conhecimento científico e técnico avançado e/ou quando se reconhecer o valor de outros conhecimentos e epistemologias ("epistemologias do sul"), para o que é necessária "uma luta pela justiça cognitiva global [que] para ser bem sucedida exige um pensamento pós-abissal" (Santos, 2009, p. 32).

Paradoxalmente, em países semiperiféricos como Portugal e Brasil, uma das críticas à universidade é a de que esta continua atrasada justamente porque não segue os padrões supostamente mais avançados de outros países. A este propósito, escreve um autor (ex-reitor): "colocar o Brasil no cenário educacional do mundo é responsabilidade da universidade. Para isso, é imprescindível que, nas relações complexas de trocas internacionais, tenhamos sistemas educacionais que sejam valorizados e compatíveis com os centros intelectuais e econômicos do mundo contemporâneo" (Almeida Filho, 2008, pp. 179-180). No entanto, como assinala Edgardo Lander, esta reação deve ter em conta "o processo ideológico da naturalização da sociedade de mercado" em que a própria produção de "pensamento não se distingue da propaganda" (Lander, 2015, pp. 46-55).

No nosso entender, uma reflexão crítica que ponha em questão as universidades do Sul Global deve passar pela tomada de consciência dos atuais processos de globalização no que diz respeito à produção do conhecimento". Não estamos aqui a posicionar-nos contra a internacionalização no ensino superior, mas a chamar a atenção para o facto de que, nas atuais condições históricas, as profundas assimetrias na mobilidade científica

\footnotetext{
"Tendo em mente as "especificidades do capitalismo" dos países centrais e o seu avanço sobre as instituições de ensino superior em economias semiperiféricas, podemos vislumbrar, na esteira do estudo de Silva-júnior (2017, p. 251), a construção de "novas universidades portuguesas e brasileiras".
} 
(de estudantes e investigadores) não deixam de algum modo de perpetuar (e até revigorar) relações neocoloniais de dominação e injustiça. Sob esta perspetiva, alinhada ao que autores pós-coloniais latino-americanos designam de des/decolonizar as universidades, acreditamos ser possível incentivar (também) a procura de rotas alternativas de internacionalização que não assentem na mera hipervalorização de projetos e estratégias individuais para uma inserção mais vantajosa no novo capitalismo financeiro e cognitivo, mas que mobilizem projetos coletivos, nomeadamente na procura de soluções científicas, técnicas, culturais e educacionais para os problemas que esse mesmo capitalismo não é capaz de resolver. Estas alternativas têm também de ser acompanhadas pela quebra do monopólio da língua inglesa, porque o "monolinguismo (inglês) é reivindicado como condição para a modernização, enquanto a multiplicidade de linguagens é um incômodo" (Barrantes-Montero, 2018, p. 5).

Aliado ao que isto significa e implica, podemos também refletir sobre o paradoxo do fenómeno da internacionalização, que ao mesmo tempo que se agiganta em razão de uma demanda ampliada, a envolver estudantes de culturas linguísticas de todo o mundo, também se empobrece por limitar-se ao imperativo da língua franca da economia global. Assim, a globalização da língua inglesa implica também na sua vulgarização, o que pode, no futuro, levar à valorização de outras línguas para efeitos de mobilidade estudantil e de mercado de trabalho. Segundo Veronica Lasanowski (2013, p. 205) "futuros empregadores buscarão, a longo prazo, cada vez mais formandos globais (leia-se multilíngue), fazendo com que a oportunidade de aprender em mais de um idioma ou de estudar em inglês em um contexto não-inglês cresça e se torne comparativamente mais popular".

Por este viés, universidades com cursos em Inglês, mas não falantes da língua inglesa, passam a disputar com Estados Unidos e Reino Unido a competição por estudantes internacionais interessados em se tornar fluentes numa segunda língua estrangeira. Para a linguista britânica, Jennifer Jenkins, esta tendência leva à construção de uma universidade "verdadeiramente internacional" porque adota o Inglês como língua franca, mas também se configura em um espaço multilingue, o que significa o ensino em uma variedade de idiomas. Porém, sublinha a autora, nas universidades anglófonas, mesmo diante de toda a retórica da diversidade, "o ethos predominante continua a ser o desatualizado de aculturação, o oposto diametral de uma abordagem multilingue" (Jenkins, 2015, pp. 78-79). Sendo assim, as universidades de países anglófonos que mais atraem estudantes internacionais acabam por perpetuar a "cultura monolingue" e deixam de se beneficiar dos "ricos recursos linguísticos e culturais que os alunos trazem consigo" (Jenkins \& Wingate, 2015, p. 48).

\section{DA NEGLIGÊNCIA À URGÊNCIA: A POLÍ́TICA DO ENSINO DE INGLÊS}

$\mathrm{Na}$ última década, a internacionalização do ensino superior tem tido grande centralidade nas estratégicas políticas do Brasil e de Portugal. Posicionados como semiperiféricos no sistema económico mundial, os dois países lusófonos investem e implementam 
programas de mobilidade na expectativa de fortalecer as suas instituições de ensino e pesquisa, e de obter vantagens no mercado internacional da educação superior. Assim, para além do já existente programa Erasmus, universidades e institutos superiores politécnicos portugueses passam a aceitar, a partir de 2014, estudantes brasileiros bem classificados nas provas nacionais aplicadas pelo Ministério da Educação do Brasil a concluintes do ensino secundário. Por sua vez, no Brasil, a internacionalização ganha relevância política com o Programa Ciência sem Fronteiras, instituído em 2011.

Em ambos os contextos, a mobilidade segue um percurso afinado com as exigências da economia do conhecimento, num padrão de regulação global em que as universidades e centros de pesquisa são qualificados por indicadores de produção de resultados. Ao lado de números que mensuram as publicações científicas, as patentes e os serviços especializados, a presença de estudantes internacionais está entre os critérios de classificação de excelência académica numa comparação mundial (Marginson, 2017, p. 7). Portanto, além de ser uma importante fonte de receita, a massa estudantil que busca a educação internacional contabiliza pontos para o status posicional destas instituições nos principais rankings mundiais. Não por acaso, a oferta de cursos e de unidades curriculares lecionados em Inglês justifica também o imperativo de reforçar a competitividade do espaço europeu de ensino superior.

Assim, as políticas de internacionalização do Brasil e de Portugal devem ser percecionadas nas suas singularidades (por vezes, antagónicas), não obstante estarem ambas imbrincadas numa agenda global hegemónica onde está em desenvolvimento um mercado da educação muito lucrativo. Para Terri Kim (2009, p. 398), estamos diante de uma mobilidade transfronteiriça que contribui para a empresarialização ${ }^{12}$ da universidade numa escala global. Este contexto não pode, por isso, deixar de ser problematizado a partir do conceito de colonialidade, uma vez que a educação formal valorizada é a hegemónica e, portanto, "apoiada e financiada por estruturas de poder nacionais e internacionais, com um claro interesse em manter o sistema educacional como um instrumento para assegurar o controle dos meios e dinâmicas de produção" (Barrantes-Monteiro, 2018, p. 3). Trata-se, pois, de uma relação de forças políticas e económicas que, na especificidade da internacionalização recente do ensino superior do Brasil e de Portugal, tem se revelado em sintonia com a agenda da globalização neoliberal.

As recentes alterações nas políticas educativas para o ensino da língua inglesa ilustram bem o que estamos a problematizar. Como vimos, a proficiência em inglês passou a somar-se ao "conjunto das habilidades internacionais" exigidas para as oportunidades

\footnotetext{
${ }^{12}$ A autora emprega o termo "corporatização" recorrente na administração/gestão de grandes empresas privadas (corporações) para aludir à gestão pública contemporânea. No paralelo ao campo da educação pública, Terri Kim observa que a adoção de um novo modelo de governança e gestão de universidades do Reino Unido prioriza a "gestão eficiente" dos recursos em educação superior, e resulta na criação de uma nova estrutura de "gerenciamento hierárquico". "Isso levou à mudança da natureza da profissão acadêmica. Os acadêmicos universitários são cada vez mais avaliados por meio de procedimentos quantitativos voltados aos negócios" (Kim, 2009, p. 397). E acrescenta mais adiante: "no geral, sugere-se que a condição contemporânea de mobilidade acadêmica transnacional é em grande parte enquadrada pela 'globalização econômica', e o regime de mercado neoliberal resultou no aumento da governança e gestão corporativista no setor de ensino superior em países como Nova Zelândia, Austrália e Reino Unido" (Kim, 2009, p. 399).
} 
de emprego em "empresas de orientação global" (Lasanowski, 2013, p. 197) 13. Por conseguinte, a competência da oralidade tem (também) ganhado ênfase nas políticas educativas destes dois países lusófonos. No Brasil, no auge do neoliberalismo na década de 1990, a oralidade não foi uma competência valorizada pela política linguística'4. O entendimento era de que "somente uma pequena parcela da população [tinha] a oportunidade de usar línguas estrangeiras como instrumento de comunicação oral, dentro ou fora do país" (MEC/SEF, 1998, p. 20). A pesquisadora brasileira Vera Lúcia Menezes de Oliveira Paiva (Amorim, 2015) critica essa visão elitista relativa ao ensino de inglês nas escolas brasileiras e afirma que, ao desconsiderar a relevância social das habilidades da escrita e da oralidade, a política reforçou a discriminação contra as classes populares, que só contavam com a escola pública para aprender um segundo idioma.

A viragem na política do ensino de língua no Brasil ocorre no início dos anos 2000 , no embalo das reformas educacionais demandadas pela economia global ${ }^{15}$. A partir de então a colonialidade de ordem interna exercida por uma elite dominante no Brasil - e que dificultava o acesso dos mais pobres à educação internacional mediante um ensino precário de língua estrangeira - é vencida por uma colonialidade de ordem externa, a impor a hegemonia do inglês para operacionalizar a máquina da internacionalização capitalista do ensino superior. Num estalar quase de dedos, o inglês deixa de ser disciplina secundária para ingressar entre as de maior status. Entretanto, não houve tempo nem fôlego no orçamento público para ser possível transpor os obstáculos e vencer a negligência histórica para um ensino de qualidade da língua inglesa nas escolas brasileiras. A instituição do Programa Ciência sem Fronteiras, em dezembro de 2011, defrontou-se com esta problemática a tal ponto que se tornou urgente a criação de políticas adjacentes para melhorar a proficiência de inglês de estudantes universitários, nomeadamente nas habilidades de oralidade e escrita, para fins de internacionalização ${ }^{16}$.

Em Portugal, as inovações nas orientações relativas ao ensino de língua inglesa processaram-se lentamente e a valorização das competências comunicativas podem ser compreendidas no contexto do Quadro Europeu Comum de Referência para as Línguas, de 2001 , tendo em vista "os desafios da enorme mobilidade internacional e de uma

\footnotetext{
13 "Esse argumento, de que a capacidade de falar inglês é altamente conducente a futuras oportunidades de emprego, vai ainda mais longe na explicação da atratividade dos destinos de língua inglesa" (Lasanowski, 2013, p. 197). E mais adiante, a autora acrescenta: "Dado que os estudantes frequentemente acreditam que as qualificações no exterior são mais valiosas que as "locais", o facto de os Estados Unidos, o Reino Unido, a Austrália, o Canadá e a Nova Zelândia oferecerem qualificações reconhecidas internacionalmente é um motivador fundamental a "puxar" estudantes internacionais em direção a eles" (Lasanowski, 2013, p. 199).

${ }^{14}$ No Brasil, o ensino de língua estrangeira foi historicamente uma disciplina secundária no currículo escolar. Apenas com a aprovação da Medida Provisória 746 de 2016, que introduziu modificações na Lei de 9.394/1996 - a Lei de Diretrizes e Bases da Educação Nacional (LDBEN), passou a ser unidade curricular obrigatória a partir do $6^{\circ}$ ano escolar. Até então era obrigatória a oferta de uma língua estrangeira, não necessariamente o inglês.
}

${ }^{15}$ As Orientações Curriculares para o Ensino Médio (OCEM), do Ministério da Educação do Brasil, no terceiro capítulo, dedicado a "Linguagens, Códigos e suas Tecnologias", traz uma seção específica sobre o ensino de línguas estrangeiras em que se problematiza a importância da proficiência em um idioma estrangeiro dada a "exclusão no ensino em face de valores 'globalizantes' e o sentimento de inclusão", comumente associado ao domínio de um idioma (MEC/SEB, 2006, p. 87).

${ }^{16} \mathrm{~A}$ baixa proficiência dos estudantes que se candidatam ao Ciência sem Fronteiras revelou-se o maior desafio para cumprir, no prazo de quatro anos, a meta de conceder 100 mil bolsas de estudo. O Ministério da Educação do Brasil viu-se pressionado a instituir o Programa Inglês sem Fronteiras, com o objetivo de propiciar a formação e a capacitação de universitários para os exames de proficiência exigidos para ingresso nas universidades anglófonas (Borges, 2018, p. 2). 
cooperação mais próxima não só nos domínios da educação, cultura e ciência, mas também nos domínios do comércio e da indústria" (Conselho da Europa, 2001, p. 22). Para tanto, conforme ainda o documento, as políticas educacionais da Europa precisam estar organizadas em níveis de ensino-aprendizagem comuns para atender as necessidades de uma Europa “multilingue" e "multicultural”. Por isso, após a publicação do QECR, para além do Inglês, uma segunda língua estrangeira passou a compor o currículo escolar e "tanto a interação oral como a produção oral passaram a ser duas das competências que adquiriram maior relevância" na agenda da política do ensino de línguas em Portugal (Martins \& Cardoso, 2015, p. 140) 17. Em suma, a política de ensino de língua inglesa em Portugal visa atingir "um domínio mais exigente e mais harmonizado com os referenciais internacionais existentes" (Decreto-Lei n 176, 2014, p. 6065).

\section{O SUbALterno Português NA MObiliddade global ESTUdANTIL}

$\mathrm{Na}$ crescente mobilidade global de estudantes, a competência de comunicar em língua inglesa tornou-se condição primordial para participar de programas de estudo e de pesquisa nas universidades melhor posicionadas nos rankings académicos, "os faróis de Alexandria", nos termos de João dos Reis Silva Júnior (2017, p. 255). Entretanto, argumentamos, com base em dados de pesquisa empírica, que esta competência pode revelar-se mais ou menos impactante nas políticas de mobilidade internacional conforme a combinação de desigualdades. Para além disso, esta soma de fatores pode estar a moldar rotas possíveis, nem sempre desejáveis, para os grupos sociais mais desfavorecidos. Com foco no domínio e no ensino do idioma inglês, apresentamos a seguir uma análise preliminar a comparar Brasil e Portugal.

Embora a escola pública portuguesa, ao contrário da brasileira, conte com uma presença significativa de alunos de classe média, ainda assim, no domínio da língua inglesa, "um número considerável de alunos chega ao ensino superior com grandes lacunas ao nível de competência oral" (Martins \& Cardoso, 2015, p. 150). Em Portugal, o Instituto de Avaliação Educativa (IAVE) do Ministério da Educação e Ciência estabeleceu em 2013 um protocolo com a Universidade de Cambridge para testes de avaliação externa do nível de Inglês nas escolas portuguesas de ensino básico. A meta traçada pelo governo visava que os alunos atingissem no final do $9^{\circ}$ ano o nível de proficiência $B_{1}$ (capacidade de comunicar sobre assuntos simples do quotidiano) de acordo com as recomendações do QECR. Os testes de língua inglesa aplicados nas escolas portuguesas nos anos 2014 e 2015 mostraram resultados piores para as competências de oralidade: $66 \%$ e $64 \%$ dos alunos do $9^{\circ}$ ano obtiveram, respetivamente, desempenho considerado weak ou bordeli$n e$, nos componentes de reading $Q$ writing e listening (Sousa et al., 2014, p. 11).

\footnotetext{
${ }_{17}$ A partir de 2007 , com a Portaria $n^{\circ} 1322$, a avaliação da oralidade passa a ser uma obrigatoriedade para as línguas estrangeiras, com $30 \%$ do peso da nota. De acordo com Martins e Cardoso (2015, p. 140), até então a oralidade em sala de aula das escolas portuguesas, seja na expressão ou na compreensão, detinha "muito pouco (ou nenhum) peso ao nível da abordagem metodológica". Em relação ao inglês, desde o ano letivo 2015/2016, com a publicação do Decreto-Lei $n^{\circ}$ $176 / 2014$, o ensino da disciplina foi antecipado em dois anos e passou a ser obrigatório no currículo das escolas portuguesas a partir do $3^{\circ}$ ano de escolaridade. Em Portugal, portanto, o ensino de inglês soma dez anos consecutivos até o fim do secundário, três a mais que no Brasil.
} 
Estes dados e o percurso cumprido até aqui levam-nos a refletir até que ponto a proficiência em língua inglesa está a restringir a mobilidade de portugueses para as universidades de elite sediadas em países anglófonos. Naturalmente, para além da questão do domínio da língua inglesa, outros fatores, nomeadamente de ordem económica, influenciam a escolha dos destinos. Entre 33 países europeus que participam do Programa Erasmus +, que conta com suporte financeiro da União Europeia, Espanha e Itália têm sido os dois principais anfitriões dos estudantes portugueses. Em 2015, estes países foram as escolhas de $34,1 \%$ dos que participaram do programa europeu de mobilidade. Por sua vez, o Reino Unido aparece no sexto lugar da lista, com 4,6\% do total de estudantes. O fluxo inverso apresenta-se bastante equilibrado, com Espanha e Itália a responderem juntas por $35,5 \%$ dos seus estudantes recebidos em Portugal. Porém, o Reino Unido aparece numa longínqua $13^{\mathrm{a}}$ posição, com apenas $1,7 \%^{18}$ (European Union, 2017).

No Brasil, o domínio da língua inglesa pelos estudantes que chegam às universidades já se revelou um problema para os programas de internacionalização, muito embora os Estados Unidos sejam o principal destino da mobilidade académica. A análise de uma amostra, composta por 1.283 participantes do Programa Ciência Sem Fronteiras (CsF), que cumpriram parte da graduação em instituições estadunidenses, entre 2012 e 2015, revela que a proficiência se encontra intimamente associada a variáveis de género, raça, classe social e trajetória escolar anterior (escola pública ou privada). Entre as competências analisadas, a conversação foi a de menor domínio, nomeadamente entre as mulheres, os negros, os mais pobres e aqueles que frequentaram escolas públicas, que, no geral, exibem menor qualidade de ensino no Brasil (Borges, 2018, pp. 129-132). Verificou-se então o quanto as desigualdades da sociedade brasileira se refletiram na mobilidade para os Estados Unidos, país que mais recebeu participantes do Ciência sem Fronteiras. Quase 60\% dos estudantes declararam ter feito curso de inglês por até 16 semanas naquele país para "aprimorar a proficiência linguística" (Borges, 2018, p. 134).

Estes dados são relevantes porque denunciam como fenómenos sociais impulsionados pela globalização da educação são permeados por uma complexa rede de relações de poder e interagem com fatores de ordem social para perpetuar e ampliar injustiças e desigualdades em distintas sociedades. No programa Ciência sem Fronteiras, por exemplo, a inexistência de barreira linguística em Portugal para estudantes internacionais do Brasil pode explicar, em grande medida, a razão pela qual as instituições portuguesas de ensino superior se tornaram a única opção para muitos estudantes. Talvez por isso, diante do elevado número de candidatos, o governo brasileiro tenha suspendido a mobilidade para Portugal, sob o argumento de que o programa também objetivava melhorar a proficiência em língua estrangeira. Em decorrência dessa ação, "a parceria com o Conselho de Reitores das Universidades Portuguesas (CRUP) foi escanteada em detrimento

\footnotetext{
${ }^{18}$ Respetivamente, 1.882 e 1.070 estudantes portugueses foram estudar na Espanha e Itália. O Reino Unido recebeu 386 estudantes portugueses em 2014. No fluxo inverso, Portugal recebeu 2.655 estudantes espanhóis e 1.822 italianos. O Reino Unido enviou 219 estudantes para instituições portuguesas em 2015 pelo Programa Erasmus+. Na Europa, o principal destino dos estudantes britânicos e da Irlanda do Norte é a França, que recebeu 24,8\% dos participantes do Erasmus+. Portugal ficou em $15^{\circ}$ lugar, sendo a escolha de 1,2\% dos 31.067 estudantes do Reino Unido que participaram do programa (tabela ANNEX 13-KA 103, European Union, 2017, pp. 32-33).
} 
de parceiros, em especial, anglófonos" (Borges \& Garcia-Filice, 2016, p. 9). Estudantes transferidos para os EUA alegaram, como motivo pela opção por Portugal, a dificuldade com a língua inglesa (Borges \& Afonso, 2017, p. 82):

o curso de idioma representa um grande passo para adquirir a bolsa porque, por exemplo, se você tem proficiência em inglês você pode aplicar para a bolsa para vários países. Não foi o meu caso. Porque eu não tinha proficiência em nenhuma língua e havia me candidatado para Portugal. (Entrevistado 1)

No meu caso, eu fui remanejado para os EUA, pois na verdade eu havia aplicado para a bolsa em Portugal. Desta forma, se não fosse este remanejo dos estudantes para outros países, eu não estaria apto a poder prestar a bolsa para os EUA, pois eu nunca tive a oportunidade de fazer um curso de inglês. (Entrevistado 2)

Muito embora os Estados Unidos sejam o principal destino de estudantes brasileiros, Portugal aparece sempre nas estatísticas oficiais na posição seguinte ${ }^{19}$. Assim, se por um lado, a língua portuguesa aparece subalterna na dinâmica da globalização hegemónica da educação, por outro lado, apresenta-se como opção contra-hegemónica para grupos de estudantes socialmente menos favorecidos e que se fazem visíveis nas rotas de mobilidade internacional. Face a um quadro de extremas desigualdades para a aquisição de competências de línguas estrangeiras, para muitos estudantes brasileiros, bem como de outras ex-colônias portuguesas, Portugal é a metrópole do conhecimento que lhes é possível alcançar. Por conseguinte, acabam por ser os filhos dos grupos sociais privilegiados, com maior capital económico e capital cultural (de que a fluência em inglês é um indicador), aqueles que têm maiores chances de adquirir o estatuto de estudante internacional e de frequentar as universidades, sobretudo dos EUA e do Reino Unido, situadas no topo dos rankings mundiais.

Uma questão fundamental que se deve colocar é a de saber se pode haver políticas públicas que fomentem a mobilidade internacional de forma mais justa e igualitária. $\mathrm{O}$ caminho pode ser encontrado, de algum modo, na forma como dermos resposta ao título deste artigo, inspirado no pensamento pós-colonial da teórica indiana Gayatri Spivak (1988) - Can the subaltern speak? Ele nos serviu de partida para problematizar as desigualdades invisibilizadas e perpetuadas pela hegemonia da língua inglesa na dinâmica da mobilidade global de estudantes. Sinalizámos a impossibilidade de construir um pensamento crítico sobre as consequências da economia capitalista do conhecimento

\footnotetext{
19 Tendo por referência as distintas modalidades de mobilidade internacional do Brasil, Portugal "se torna o quinto país mais popular, provavelmente devido a compartilharmos a mesma língua" (CAPES, 2017, p. 45). Entretanto, diferentemente de Portugal, onde a mobilidade ocorre desde o nível de licenciatura, nomeadamente com o Erasmus+, no Brasil o foco, após o declínio do Ciência sem Fronteiras em 2016, centra-se na pós-graduação. Ainda assim, um estudo com 312 instituições brasileiras de ensino superior, divulgado em outubro de 2017 pelo Ministério da Educação, coloca "Portugal em segundo lugar com 1\% a menos somente que os EUA na percentagem de solicitação de bolsas (de pós-graduação) em 2016" (CAPES, 2017, p. 13).
} 
sem pôr em questão a colonialidade do poder/saber que, até onde fomos capazes de discorrer, se revela entrelaçada a novas formas de dominação, exploração e produção de desigualdades.

\section{Agradecimentos}

Este trabalho é financiado pelo CIEd - Centro de Investigação em Educação, projetos UID/CED/1661/2013 e UID/CED/1661/2016, Instituto de Educação, Universidade do Minho, através de fundos nacionais da FCT/MCTES-PT.

\section{REFERÊNCIAS}

Afonso, A. J. (2017). Prefácio. Da universidade à commoditycidade: mudança ou metamorfose na educação superior? In L. Bianchetti \& V. Sguissardi (Eds.), Da universidade à commoditycidade: ou de como e quando, se a educação/formação é sacrificada no altar do mercado, o futuro da universidade se situaria em algum lugar do passado (pp. 7-12). Campinas: Mercado de Letras.

Almeida-Filho, N. (2008). Universidade nova no Brasil. In B. de S. Santos \& N. Almeida-Filho, A Universidade no século XXI: para uma universidade nova (pp. 79-184). Coimbra: Almedina/CES.

Amorim, R. (2015, 10 de junho). "É preciso investir na formação dos professores" [Entrevista a Vera Lúcia Menezes de Oliveira e Paiva].Jornal do Professor. Retirado de http://portaldoprofessor.mec.gov.br/ noticias.html?idEdicao $=129 \&$ idCategoria $=8$

Barrantes-Monteiro, L. G. (2018). Phillipsons's Linguistic Imperialism Revisited at the light of Latin American Decoloniality Approach. Revista Electrónica Educare, 22(1), 1-19. DOI: 10.15359/ree.22-1.1

Borges, R. A. (2018). Do Brasil aos EUA: a barreira do inglês na mobilidade de estudantes. Um estudo sobre identidades e desigualdades refletidas no Programa Ciência sem Fronteiras. Berlim: Novas Edições Acadêmicas.

Borges, R. A. \& Afonso, A. J. (2017). Brasil e Portugal: a mobilidade estudantil no espaço da internacionalização. In G. S. Carvalho \& M. L. Dionísio (Eds.), Encontro Nacional de Jovens Investigadores em Educação - Livro de Resumos do II ENJIE (pp. 79-84). Braga: CIEd e CIEC.

Borges, R. A. \& Garcia-Filice, R. C. (2016). Entre Portugal e Estados Unidos: o impacto das desigualdades em duas rotas do Programa Ciência sem Fronteiras. In Portugal, Território de Territórios - Livro de atas do IX Congresso Português de Sociologia. Lisboa: Associação Portuguesa de Sociologia. Retirado de http://www. aps.pt/ix_congresso/actas

Conselho da Europa. (2001). Quadro Europeu Comum de Referência para as línguas: aprendizagem, ensino, avaliação. Porto: Edições ASA. Retirado de http://www.dge.mec.pt/ quadro-europeu-comum-de-referencia-para-linguas

Coordenação de Aperfeiçoamento de Pessoal de Nível Superior - CAPES. (2017). A internacionalização na Universidade Brasileira: resultados do questionário aplicado pela CAPES. Brasília: Diretoria de Relações Internacionais da CAPES/MEC.

Cunha, A. \& Santos, Y. (2017). Erasmus'30. A história do programa e a participação dos estudantes portugueses. Lisboa: Letras Errantes/Bookbuilders.

Decreto-Lei $n^{\circ}$ 176/14. (2014). Inglês como disciplina obrigatória a partir do $3^{\circ}$ ano. Diário da República, $1^{a}$ série, 240, 6064-6068. Ministério da Educação e da Ciência. 
European Union. (2017). ANNEX 13 - KA 103 - Higher Education mobility within programme countries - Students by sending/receiving country - Call 2015. Annual Report 2016. Statistical Annex Erasmus+. Enriching lives, opening minds. Bruxelas: European Commission.

Holford, J. (2014). The lost honour of the social dimension: Bologna, exports and the idea of the university. International Journal of Lifelong Education, 33(1), 7-25. DOI: 10.1080/02601370.2013.873210

Jenkins, J. (2015). Repositioning English and multilingualism in English as a Lingua Franca. Englishes in Practice, 2(3), 49-85. DOI: 10.1515/eip-2015-0003

Jenkins, J. \& Wingate, U. (2015). Staff and students' perceptions of English language policies and practices in 'international' universities: a case study from the UK. Higher Education Review, 47(2), 47-73.

Kim, T. (2009). Transnational academic mobility, internationalization and interculturality in higher education. Intercultural Education, 20(5), 395-405. DOI: 10.1080/14675980903371241

Lander, E. (2015). Conocimiento para que? Conocimiento para quién?Reflexiones sobre la universidad y la geopolítica de los saberes hegemónicos. In Z. Palermo, S. Castro-Gómez, E. Lander, W. Mignolo, R. Segato \& C. Walsh, Des/decolonizar la universidad (pp. 41-67). Ciudad Autónoma de Buenos Aires: Del Signo.

Lasanowski, V. (2013). Can speak, will travel: the influence of language on global student mobility. In R. Bhandari \& P. Blumenthal (Eds.), International students and global mobility in higher education (pp. 193209). Nova Iorque: Palgrave Macmillan.

Marginson, S. (2017). Do rankings drive better performance? International Higher Education, 89, 6-8. DOI: $10.6017 /$ ihe.2017.89.9762

Martins, C. S., \& Cardoso, M. N. (2015). Let's talk, shall we? A oralidade no ensino do inglês em Portugal. Saber a Educação. Perspetivas Didáticas e Metodológicas no Ensino Básico, 20, 138-158.

Mignolo, W. (2010). Desobediência epistémica: retórica de la Modernidad, lógica de la colonialidad y gramática de la colonialidad. Buenos Aires: Ediciones Del Signo.

Ministério da Educação. (1998). Parâmetros curriculares nacionais. Terceiro e quarto ciclos do Ensino Fundamental. Língua estrangeira. Brasília: Secretaria de Educação Fundamental (MEC/SEF).

Ministério da Educação. (2006). Linguagens, códigos e suas tecnologias. Orientações curriculares para o Ensino Médio, vol.1. Brasília: Secretaria de Educação Básica MEC/SEB).

Nogueira, M. A. (2017). Quando a meritocracia se vê ameaçada, o que ocorre com os padrões (históricos) da excelência escolar? In L. L. Torres \& J. A. Palhares (Eds.), A excelência académica na escola pública portuguesa (pp. 228-235). Vila Nova de Gaia: Fundação Manuel Leão.

Portaria $n^{0}$ 1322/07. (2007). Define carga horária de língua estrangeira. Diário da República, $1^{a}$ série, 192, $7107-7123$.

Quijano, A. (2002). Colonialidade, poder, globalização e democracia. Novos Rumos, 37(17), 4-28.

Santos, B. de S. (2009). Para além do pensamento abissal: das linhas globais a uma ecologia dos saberes. In B. de S. Santos \& M. P. Meneses (Eds.), Epistemologias do Sul (pp. 23-71). Coimbra: Almedina/CES.

Santos, E. \& Schor, P. (2013). Brasil, estudos pós-coloniais e contracorrentes análogas: entrevista com Ella Shohat e Robert Stam. Estudos Feministas, 21(2), 701-725. DOI: 10.1590/So104-026X2013000200020

Silva-Júnior, J. dos R. (2017). The new Brazilian university. A busca por resultados comercializáveis: para quem? Bauru: Canal 6. 
Sousa, H., Marôco, J., Sampaio, M. M., Simões, P., Pereira, S. \& Castanheira, T. (2014). Teste key for schools. Resultados 2014. Sumário executivo. Lisboa: Instituto de Avaliação Educativa (IAVE)/MEC.

Spears, E. (2014). O valor de um intercâmbio: mobilidade estudantil brasileira, bilateralismo \& internacionalização da educação. Revista Eletrônica de Educação, 8(1), 151-163. DOI: $10.14244 / 198271991026$

Spivak, G. C. (1988). Can the Subaltern Speak? In C. Nelson, L. Grossberg, C. Nelson, \& L. Grossberg (Eds.), Marxism and the interpretation of culture (pp. 271-313). Urbana; Chicago: University of Illinois Press.

Unesco. (2000). Science for the twenty-first century. A new commitment. Declaration on sciense and the use of scientific knowledge. Science agenda-framework for action. Retirado de http://unesdoc.unesco.org/ images/0012/001229/122938eo.pdf

Unesco Institute for Statistics. (2018). Global flow of tertiary-level students. Retirado de http://uis.unesco.org/ en/uis-student-flow

Viana, C. (2018, 25 de março). Greve também é sinónimo de universidade? No Reino Unido, sim. Público, pp. 14-15.

\section{NOTAS BIOGRÁFICAS}

Rovênia Borges é doutoranda em Ciências da Educação (Política Educativa) e investigadora do Centro de Investigação em Educação do Instituto de Educação da Universidade do Minho, Portugal. Mestre em Educação e licenciada em Comunicação Social/ Jornalismo pela Universidade de Brasília, Brasil.

ORCID: https://orcid.org/oooo-0001-8259-5623

Email: roveniaa@gmail.com

Morada: Ministério da Educação, Bloco L, Edifício-Sede, Sala 903, Esplanada dos Ministérios, 70047-900, Brasília, DF, Brasil

Almerindo Afonso é sociólogo, Doutor em Educação, Professor Associado do Departamento de Ciências Sociais da Educação e investigador do Centro de Investigação em Educação da Universidade do Minho, Portugal.

ORCID: http://orcid.org/oooo-0o01-9879-5814

Email: ajafonso@ie.uminho.pt

Morada: Instituto de Educação, Universidade do Minho, Campus de Gualtar, 4710057, Braga, Portugal

\section{* Submetido: 14.05 .2018 \\ * Aceite: 12.07.2018}

